\title{
EXPERIÊNCIAS DOCENTES NA FORMAÇÃO INICIAL: O PROCESSO FORMATIVO DE PROFESSORES DE EDUCAÇÃO FÍSICA
}

\author{
EXPERIENCIAS EN ENSEÑNAZAS BÁSICAS DE ENTRENAMIENTO: EL PROCESO \\ DE FORMACIÓN DE PROFESORES DE EDUCACIÓN FÍSICA
}

\section{TEACHING EXPERIENCES IN INITIAL TRAINING: THE TRAINING PROCESS OF TEACHERS OF PHYSICAL EDUCATION}

\author{
Victor Julierme Santos da CONCEIÇÃO ${ }^{1}$ \\ Jessica Serafim FRASSON ${ }^{2}$ \\ Elisandro Schultz WITTIZORECKI ${ }^{3}$ \\ Hugo Norberto KRUG ${ }^{4}$
}

RESUMO: O objetivo dessa pesquisa foi compreender quais experiências docentes assumem protagonismos no processo formativo dos estudantes do curso de Licenciatura em Educação Física da Universidade do Extremo Sul Catarinense (UNESC). Para isso, entrevistamos cinco estudantes de graduação (quatro mulheres e um homem) que cursavam a oitava fase do curso de licenciatura em Educação Física, que já haviam concluído todos os estágios curriculares obrigatórios e as práticas como componente curriculares ofertadas pelo curso. Compreendemos que o constituir-se professor é um processo carregado de ações e sentidos, movidos por saberes que mobilizam a prática pedagógica dos estudantes em formação inicial, por meio das reflexões críticas sobre o seu exercício docente.

PALAVRAS-CHAVE: Experiência docente. Processo formativo. Educação física. Formação inicial.

RESUMEN: El objetivo de esta investigación fue entender lo que experimenta maestros asumen protagonismo en el proceso de formación de los estudiantes de la Licenciatura en Educación Física de la Universidade do Extremo Sul Catarinense (UNESC). Para ello, se entrevistó a cinco estudiantes graduados (cuatro mujeres y un hombre) que asistieron a la octava etapa del curso de licenciatura en Educación Física, que ya había completado todas las prácticas y las prácticas obligatorias como componente curricular que ofrece el curso. Entendemos que constituyen maestro es un proceso completo de acciones y los sentidos, movidos por el conocimiento que movilizan la práctica pedagógica de los estudiantes en la formación inicial, a través de la reflexión crítica sobre su práctica docente.

${ }^{1}$ Universidade Federal de Santa Catarina (UFSC), Florianópolis - SC - Brasil. Centro de Ciências da Educação.
Programa de pós-graduação em Educação. Doutor em Ciências do Movimento Humano/ Universidade Federal
do Rio Grande do Sul. E-mail: victorjulierme@ yahoo.com.br
${ }^{2}$ Universidade Federal do Rio Grande do Sul (UFRGS), Porto Alegre - RS - Brasil. Doutoranda no programa de
Pós-graduação em Ciências do Movimento Humano. ORCID: http://orcid.org/0000-0002-6142-1971. E-mail:
jehfrasson@ hotmail.com
${ }^{3}$ Universidade Federal do Rio Grande do Sul (UFRGS), Porto Alegre - RS - Brasil. Doutor em Ciências do
Movimento Humano. ORCID: http://orcid.org/0000-0001-7825-0358. E-mail: elisandrosw @ gmail.com
${ }^{4}$ Universidade Federal de Santa Maria (UFSM), Santa Maria - RS - Brasil. Doutor em Educação. ORCID:
http://orcid.org/0000-0001-8985-9011. E-mail: hnkrug@bol.com.br RIAEE - Revista Ibero-Americana de Estudos em Educação, Araraquara, v. 14, n. 4, p. 2106-2122, out./dez., 2019. e-ISSN: 1982-5587. DOI: https://doi.org/10.21723/riaee.v14i4.9748 
PALABRAS CLAVE: Experiencia en la enseñanza. Proceso de formación. Educación física. Formación inicial.

ABSTRACT: The objective of this research was to understand which teaching experiences take center stage in the training process of the undergraduate students in Physical Education at the University of Extremo Sul Catarinense (UNESC). To do this, we interviewed five undergraduate students (four women and one man) attending the eighth phase of the undergraduate degree in Physical Education, who had already completed all the compulsory curricular internships and practices as curricular components offered by the course. We understand that becoming a teacher is a process full of actions and senses, driven by knowledge that mobilizes the pedagogical practice of students in initial formation, through critical reflections on their teaching.

KEYWORDS: Teaching experience; Formative process; Physical education; Initial formation.

\section{Introdução}

Do mesmo modo que Silva e Almeida Junior (2010), consideramos a formação docente como um processo, e este se concretiza por diferentes momentos na constituição do ser professor. Para Nóvoa (1992), a formação toma uma noção de autoformação; Pimenta (2005, p. 29-30) contribui no debate afirmando que pensar ela - formação - assim autoformação - "é pensar um projeto único, desde a formação inicial até a continuada". Caldeira (2001) observa que a formação de professores é composta pelas experiências vividas antes da vida acadêmica, pela formação inicial e pelas experiências vividas durante a docência. Neste sentido, assumimos a noção de que a formação inicial é um momento importante do processo contínuo que é formar-se professor, contudo precisa ser olhada/entendida/analisada conjuntamente com outras dimensões que concorrem com esse processo. Nesse sentido, a socialização que ocorre nos primeiros anos de docência na escola, os marcos legais que orientam as esferas formativas e o próprio percurso pessoal de formação precisam ser considerados conjugadamente à formação inicial.

Assim, é possível pensar que a formação inicial se constitui também pelo envolvimento dos sujeitos que atravessam tal processo, pelas relações entre os professores formadores e os professores em formação, pelos conhecimentos construídos e reconstruídos, pelas vivências e experiências formuladas durante todo o processo. Flores (2010) destaca que uma das intenções da formação inicial é também preparar os futuros professores para trabalharem em escolas e em contextos diversos. 
Com isso, os futuros docentes durante seus cursos de formação inicial articulam suas crenças com os conteúdos, com as didáticas utilizadas pelos seus professores, e com as novas experiências propiciadas por esta formação (MARCELO GARCIA, 2010), experiências essas que podem se caracterizar pelos estágios obrigatórios, pelas práticas como componentes curriculares, pelas disciplinas, e também pelos diálogos entre os colegas e seus formadores. Em outras palavras, ao longo da formação inicial de professores, os sujeitos vão sendo paulatinamente inscritos na cultura docente (MOLINA NETO, 1996). Por cultura docente entendemos como o que é compartilhado pelos professores; expressa, portanto, um conjunto de crenças, práticas e princípios éticos balizadores da ação pedagógica do professor, e que exerce forte influência na forma como as interações comunicativas e relacionais são arquitetadas na sala de aula e na escola.

Além disso, é importante ressaltar que os acadêmicos chegam às universidades carregados de um capital cultural construído nas suas experiências com o mundo de vida. Ou seja, trazem consigo seus traços identitários, que são incorporados ou interiorizados (DUBAR, 1996; BERGER; LUCKMANN, 2012) pelas suas primeiras experiências sociais (DUBET, 1994). Flores (2010, p. 182) apresenta que "os futuros professores possuem um conjunto de crenças e de ideias sobre o ensino e sobre o que significa ser professor que interiorizaram ao longo da sua trajetória escolar". Figueiredo (2008) também nos ajuda a pensar sobre as experiências sociais dos estudantes na transição do ensino médio para o ensino superior: a autora destaca que a bagagem cultural pode influenciar na escolha do curso superior. Isso, devido ao próprio tempo em que os acadêmicos vivem e são socializados como estudantes, da pré-escola a universidade.

Neste sentido, a experiência docente não pode ser limitada aos momentos em que o futuro professor inicia o seu curso de formação inicial, mas antes mesmo, o que caracterizamos como uma experiência pré-docente, atendendo suas várias passagens pelas instituições de ensino. Pensando de modo próximo a Carlos Marcelo (2010, p. 12), entendemos que a docência é uma das profissões "nas quais os futuros profissionais se veem expostos a um período mais prolongado de socialização prévia”. Mizukami (1996) corrobora com a ideia ao apresentar que constituir-se professor é um caminho que tem início nas primeiras vivências escolares.

Em síntese, compreendemos a formação como um processo permanente e dinâmico. Ainda ressaltamos que essa formação não é apenas acadêmica ou científica, e sim formação humana, com o vivido, o experienciado pelos sujeitos sociais. 
Dubet (1994), Contreras Domingo (2013), Contreras Domingo e Pérez de Lara (2010) nortearam o debate sobre experiência proposto pela pesquisa. Neste sentido, Dubet (1994) apresenta em seus estudos três princípios de análise para tratar a noção sociológica da experiência, que trabalham com o distanciamento do ator e o sistema, ou seja, um conjunto heterogêneo de lógicas de ação.

A sociologia da experiência tem em vista definir a experiência como uma combinação de lógicas de acção, lógicas que ligam o actor a cada uma das dimensões de um sistema. O actor é obrigado a articular lógicas de acção diferentes, e é a dinâmica gerada por esta atividade que constitui a subjectividade do actor e a sua reflectividade (DUBET, 1994, p. 107).

Nesse sentido, o objeto da sociologia da experiência tratada por Dubet (1994) é a subjetividade dos atores: quanto mais eles se afastam das ações propostas e impostas pela sociedade, mais eles se constituem como participantes desta, como donos das suas subjetividades, dos seus saberes e das suas ações. Tanto Dubar (1996) como Berger e Luckmann (2012) apresentam que a incorporação e interiorização das pautas sociais pelos sujeitos se dá pela subjetividade, quando estes além de incorporarem o que lhes é destinado, passam a agir no mundo, no social, ou seja, primeiramente se reconhecem no mundo do outro - incorporação pelos familiares e escola - $\left(\right.$ socialização primaria $\left.^{5}\right)$, depois passam a assumir o seu mundo - compreensão e questionamentos de determinadas situações e regras - (transição da socialização) e posteriormente reconhecem o mundo - assumem suas culturas e passam a influenciar nela também - (socialização secundária), mas é importante ressaltar que essa incorporação e transição não acontece sem tensionamentos, ou seja, os sujeitos se mobilizam em busca de suas verdades e de seus entendimentos.

Deste modo, para Dubet (1994, p. 95), “a experiência social não é uma 'esponja', uma maneira de incorporar o mundo por meio das emoções e das sensações, mas uma maneira de construir o mundo". Em outras palavras, ela - experiência social - pode ser compreendida de modo que os indivíduos precisam produzir, eles mesmos, o sentido de sua ação, suas motivações, suas identidades. Evidentemente, eles constroem sua experiência a partir de recursos, de modelos culturais e de condições sociais que lhes são impostas.

Aproximando o debate sociológico do pedagógico, invocamos Contreras Domingo $\left(2013\right.$, p. $130^{6}$ ), ao definir o saber da experiência, como "o conhecimento que você precisa para as dimensões subjetivas, pessoais com as próprias histórias que nos constituem como sujeitos desde de onde vivemos, pensamos e agimos". Para o autor, esse saber da experiência

${ }^{5}$ Nossa compreensão de socialização deriva de Berger e Luckmann (2012)

${ }^{6}$ Tradução de responsabilidade nossa.

RIAEE - Revista Ibero-Americana de Estudos em Educação, Araraquara, v. 14, n. 4, p. 2106-2122, out./dez., 2019. e-ISSN: 1982-5587. 
é um conhecimento que emerge do cotidiano do sujeito, das suas relações, suas vivências e, principalmente, sobre si mesmo, da sua subjetividade. Para Contreras Domingo e Pérez de Lara $\left(2010^{7}\right.$, p. 25), a "experiência e a subjetividade são inseparáveis e supõem, entre outras coisas, o constante surgimento de novos modos de ver e de estar no mundo a partir da diferença, a partir do singular”.

Assim, podemos observar que há uma convergência entre a sociologia e a pedagogia quando Dubet (1994), Contreras Domingo (2013), Contreras Domingo e Pérez de Lara (2010) entendem que a subjetividade dos sujeitos se encontra como o elemento principal da experiência, onde estes são constituintes da sua própria história. Deste modo, propomos como objetivo do estudo compreender quais experiências docentes assumem protagonismo no processo formativo dos estudantes do curso de Licenciatura em Educação Física da Universidade do Extremo Sul Catarinense (UNESC).

\section{Metodologia}

Esta pesquisa, de caráter qualitativo interpretativo, destaca, a partir da análise de conteúdo, elementos importantes, singulares e comuns sobre a construção docente ainda em situação de estágio curricular. Do ponto de vista da pesquisa qualitativa entendemos que as generalizações não fazem parte deste universo, portanto procuramos aprofundar o debate sobre uma realidade específica, acreditando que este movimento possa contribuir com o acúmulo de conhecimento sobre o processo formativo do professor (DENZIN; LINCOLN, 2006).

É importante ressaltar que a escolha por essa instituição se deu pelo devido envolvimento de dois de nós a um determinado tempo, onde um atua como professor de estágio do curso na universidade e a outra foi acadêmica e bolsista de iniciação cientifica. Ainda compreendemos que, mesmo pensando singularmente, podemos revelar pontos interessantes e potentes para compreender e analisar outros ambientes de formação de professores em Educação Física.

Para escolha dos estudantes, colaboradores da pesquisa, utilizamos como critério tipológico os seguintes elementos: ter experiência docente diversificada durante a graduação, sob forma de estágios e projetos; ter ministrado aulas em escolas de ensino público; e, ter envolvimento com grupos de pesquisas ou programas de iniciação à docência. Os estudantes também foram selecionados pela participação espontânea, levando em consideração a 
iniciativa em buscar participação direta na investigação. Esse tipo de participação influencia positivamente no volume e credibilidade de informações disponibilizadas pelos estudantes (MOLINA NETO, 2010). Deste modo, do total de 18 estudantes matriculados na oitava fase do curso de licenciatura em Educação Física, entrevistamos quatro mulheres e um homem que já haviam realizado os estágios e as práticas como componentes curriculares ofertadas pelo curso.

Como instrumento de coleta de informações, utilizamos a entrevista semiestruturada, que para Negrine (2010) permite que se realizem explorações não previstas, oferecendo liberdade ao entrevistado para dissertar sobre o tema ou aspectos que sejam relevantes. A entrevista foi desenvolvida a partir de um roteiro semiestruturado com pontos relacionados aos aprendizados e às formas como os estudantes compreendiam a sua docência e o fazer cotidiano, levando em consideração as suas experiências no estágio curricular obrigatório. Como procedimentos para coleta de dados, entramos em contato com os estudantes para explanação do objetivo do estudo e agendamento das entrevistas, que foram realizadas individualmente em horário e local decidido em comum acordo entre pesquisadores e estudantes colaboradores da pesquisa.

Todos os estudantes colaboradores da pesquisa receberam nomes fictícios (Bruna; Maria; Marta; Clara; João) para preservar a identidade e manter os aspectos éticos da pesquisa. Além disso, as entrevistas foram gravadas, transcritas e passaram por um processo de validação interpretativa quando apresentadas aos estudantes para análise da fidedignidade das informações. Para o processo de análise, realizamos a triangulação das informações entre as entrevistas transcritas, as conversas com os acadêmicos e o referencial teórico que apoiou o processo analítico da pesquisa (TRIVIÑOS, 1987). Com as entrevistas transcritas e validadas, iniciamos a categorização das unidades de significados, que posteriormente foram agrupadas por blocos temáticos e que deram origem a duas categorias de análises: Experiências formativas: constituindo-se professor e mobilizando saberes; e, Formação inicial e o mundo de trabalho: o que esperam os professores em formação?

\section{Experiências formativas: constituindo-se professor e mobilizando saberes}

O processo formativo dos acadêmicos se inicia antes mesmo da escolha do magistério, em suas experiências como estudante da escola básica, sobre influência dos antigos professores e também de seus familiares. Ao entrar nos cursos de formação inicial, esse processo tende a se intensificar, ou seja, inicia-se um percurso de aproximações e novas 
descobertas sobre a docência com os estágios; as práticas como componentes curriculares; os diálogos com os outros colegas e professores; e ainda as disciplinas e o currículo do próprio curso (MIZUKAMI, 1996).

No campo da sociologia da experiência, Dubet (1994) admite uma dimensão subjetiva no sistema escolar, a qual é reforçada pela ideia de que o indivíduo não se forma através da internalização pura e simples de valores externos, mas através do controle da própria experiência. Neste sentido, tão importante quanto compreender a caminhada dos estudantes durante a formação inicial é entender o que levou nossos estudantes a escolher cursar Educação Física.

'Me inspirei em uma professora de Educação Física, sempre brincava que iria fazer Educação Física e não imaginava que iria realmente fazer' (Estudante Maria).

Soares (2002) aborda que a identidade é construída nas relações estabelecidas entre pessoas que desempenham papéis sociais importantes na vida de cada indivíduo. Sendo assim, suas escolhas se constituem através de vínculos que são construídos no seu percurso de vida pessoal e profissional.

Já as estudantes Marta e Clara afirmam que as suas decisões foram alimentadas pela aproximação e gosto pela prática esportiva.

'Eu tinha escolhido por gostar de esportes, mas depois, eu ganhei bolsa de estudos' (Estudante Marta).

'Eu jogava futsal, tentei entrar no time na Unesc, eu fiquei três meses jogando, mas eu tive que parar porque eles demoram aceitar para pagar a bolsa, então tinha que trabalhar' (Estudante Clara).

Observamos que a opção pelo curso de Educação Física se manifestou nas estudantes devido ao gosto da prática esportiva, mas principalmente por conseguir bolsa de estudos, como reporta a estudante Marta. Deste modo, o contato com o esporte teve influência na sua decisão pela docência. Tardif (2002) observa que uma boa parte do que os professores sabem sobre o ensino, sobre os papéis do professor e sobre como ensinar, provém de sua história de vida, principalmente de sua socialização enquanto alunos. Esse interesse pelo saber tem um processo longo de vida, acompanhado de conhecimentos anteriores, crenças e atuações na sua vida pessoal e como estudante. 
Os estudantes João e Bruna tiveram dúvidas para escolher o que cursar ao se aproximarem do ingresso no ensino superior. Arriscaram no momento da escolha, mas afirmam que durante o curso se identificaram com a docência.

\begin{abstract}
'Eu sempre quis ser professor. Mas quando foi para entrar na graduação eu fiquei indeciso em duas, Educação Física e Matemática, mas sempre pensando em ser professor' (Estudante João).

'Na verdade eu fiz seis fases de ciências contábeis e acabei não me agradando do curso. Então resolvi fazer o ENEM, e escolhi cinco cursos bem distintos um dos outros, e deu certo que consegui bolsa na Educação física, aí aproveitei que era o mais próximo da minha casa e escolhi. E ainda bem que me identifiquei com curso' (Estudante Bruna).
\end{abstract}

Mais uma vez, a opção pela bolsa de estudo se destaca na fala dos estudantes. Quanto a isso podemos analisar que a importância do que cursar é apresentada pelo mérito financeiro, ou seja, a premiação da bolsa se apresenta como divisor de águas nas escolhas dos estudantes. Se eu ganhar nesse curso, eu faço; se ganhar no outro, também. Neste sentido, podemos analisar que não há uma intencionalidade objetiva em relação à escolha da sua futura profissão, o que pode acarretar encontros e desencontros dentro do curso de formação inicial. No caso de Bruna e João, podemos identificar o desejo pelo encontro com a docência.

Nesse processo de encontros e desencontros na formação inicial é possível identificar que os estudantes passaram por inúmeras vivências práticas e teóricas no curso, e que ingressaram no curso de Licenciatura em Educação Física com muitas expectativas em relação aos conhecimentos adquiridos e construídos no período de sua formação inicial.

Essas expectativas para os estudantes João e Bruna se concentraram nos estágios propostos.

\begin{abstract}
'Os estágios, te preparam muito para elaboração de planos, fundamentação dos planos de aula, mas para a prática não. É pouco tempo, seis aulas ministradas é pouco tempo. Não dá para construir mais elementos, para avançar, e principalmente para conhecer a escola, por isso optei por fazer dois estágios na mesma escola, pra poder estar mais integrado a cultura e conhecer mais os alunos, docentes e direção' (Estudante João).

'Como meu único contato com a escola foi de quando era aluna, queria com os estágios me aproximar do meu futuro campo de atuação e aprender tudo, como dar aula' (Estudante Bruna).
\end{abstract}

Com base nas falas acima identificamos significados atribuídos ao estágio curricular. No caso da estudante Bruna, compreendemos que é um meio de se aproximar da realidade onde futuramente vai atuar. Para o estudante João, o estágio se torna o momento onde pretende conhecer a cultura escolar, por isso a opção de realizar dois de seus estágios na mesma escola, com o intuito de aprofundar a sua imersão no contexto escolar. Ambos os 
estudantes destacam que o tempo de atuação no estágio é pequeno, o que pode fragilizar o seu aprendizado.

Identificamos a crítica traçada pelos estudantes João e Bruna pelo fato de que mais tempo de estágio pode potencializar suas experiências em relação a sua prática educativa. Ainda entendemos que ler e compreender a cultura escolar demanda tempo e densidade, que pode influenciar diretamente no percurso formativos dos estudantes.

Relacionando as experiências construídas através dos estágios foi possível identificar a ideia de "confiança" como elemento pedagógico. Em outras palavras, a construção e sustentação de uma posição que minimizasse o medo pela regência. Maria e Marta destacam que a falta de previsão e do inesperado nas aulas caracterizava um momento de angústia, por não saber como agir em determinados momentos e situações.

\section{'Eu esperava aprender a perder um pouco o medo de dar aula, foi assim que eu consegui, perder um pouquinho do medo, daquele receio de estar lá na frente falando todo mundo estar te olhando, prestando atenção, foi isso que consegui perder' (Estudante Maria). \\ 'A gente sempre espera que dê certo né, sempre aquele nervosismo mas, assim, as situações são inesperadas, nunca sabemos o que vai acontecer, precisamos estar preparados' (Estudante Marta).}

Pelas falas das estudantes Marta e Maria, compreendemos que esse temor e angústia foi amenizando no decorrer do curso. Com o passar dos estágios, conseguiam sentir seus progressos e identificar situações que fogem do planejamento dos professores, que não estão previstas, mas que precisam ser contornadas. Assim, essa compreensão de que nada é estanque, tudo está em movimento, imprime nos estudantes o sentimento de progresso em relação a sua profissão.

Tardif e Raymond (2000) reconhecem que é no início da carreira que a estruturação do saber experiencial é mais forte, estando ligada à experiência de trabalho. Esses encontros e desencontros, caracterizados pelas experiências construídas nos momentos de estágios - tal como é fortemente evocado pelos estudantes - proporcionam aos futuros professores, progressivamente, certezas em relação ao contexto de trabalho, possibilitando assim a sua integração aos seus futuros ambientes profissionais.

Para Tardif (2002), é através dessas vivências anteriores, momentâneas e posteriores às suas formações, que os futuros professores constroem e mobilizam seus saberes cotidianos. Para o autor, "a noção de "saber" remete a um sentido amplo que engloba os conhecimentos, as habilidades (ou aptidões) e as atitudes dos docentes, ou seja, aquilo que foi muitas vezes chamado de saber, de saber-fazer e de saber-ser". (p. 60). O autor ainda o divide em quatro: 
saberes disciplinares, curriculares, formação profissional (das ciências da educação e da ideologia pedagógica) e da experiência ${ }^{8}$.

No mesmo caminho, Pimenta (2005, p. 08) entende que,

O saber do professor se fundamenta na tríade saberes das áreas específicas, saberes pedagógicos e saberes da experiência. É na mobilização dessa tríade que os professores desenvolvem a capacidade de investigar a própria atividade e, a partir dela, constituírem e transformarem seus saberes-fazeres docentes.

Gauthier et al. (2006) apresenta a existência de um saber efetivamente específico à classe profissional dos professores, que é o saber da ação pedagógica, resultado da relação de complementação estabelecida entre os demais saberes do professor, que o direcionam a decidir por esta ou aquela ação em cada caso específico de sala de aula.

Compreendemos que o constituir-se professor é carregado de ações e sentidos. Esses, por sua vez, são movidos por saberes que mobilizam a prática pedagógica dos futuros professores por meio das reflexões críticas sobre o seu exercício docente. Assim, podemos identificar nas entrevistas realizadas que os acadêmicos em formação tendem a supervalorizar as disciplinas cursadas, ou seja, estas se destacam em detrimento aos outros saberes, pois ao questionarmos sobre os elementos mais significativos do processo formativo dos estudantes, apenas a Estudante Maria apontou o estágio.

'O estágio é bastante importante, é uma experiência né, tem gente que nunca atua, quando eu fui fazer o primeiro estágio eu já estava trabalhando, então tem gente que a primeira experiência é no estágio, eu acho que o estágio é o mais importante' (Estudante Maria).

'Pra mim foram as disciplinas e os professores, pois eu consegui incorporar o que foi passado, e depois de um certo tempo posso retornar aos meus cadernos e livros. Mas a base de tudo são as disciplinas' (Estudante Bruna). 'No meu ponto de vista, são as disciplinas que tratam das propostas da educação Física, as propostas críticas da educação Física' (Estudante João).

'As disciplinas, e as que me marcaram são aquelas que a teoria e a prática estão juntas' (Estudante Clara).

'Eu acho que todas as disciplinas são especiais. Elas são as bases' (Estudante Marta).

${ }^{8}$ Os Saberes de formação profissional segundo o autor, são conjuntos de conhecimentos transmitidos pelas instituições de formação de professores; os Saberes da experiência são os adquiridos no cotidiano, tanto de experiências individuais como coletivas; Os curriculares são conhecimentos relacionados à forma como as instituições educacionais fazem a gestão dos conhecimentos socialmente produzidos e que devem ser transmitidos aos estudantes (saberes disciplinares); Os saberes disciplinares são os saberes reconhecidos e identificados como pertencentes aos diferentes campos do conhecimento (linguagem, ciências exatas, ciências humanas, ciências biológicas, etc.). 
De acordo com Tardif (2002, p. 38), esses saberes são “[...] produzidos pelas ciências da educação, adquiridos através da sua formação na universidade". Assim, conseguimos analisar que os saberes disciplinares apresentados por Tardif (2002) e Gauthier et al. (2006) ganham destaque na interpretação sobre o processo formativos dos nossos estudantes pelo fato destes apresentarem as disciplinas como as bases para sua prática docente. Isso pode se dar pelo fato que "os saberes das disciplinas emergem da tradição e dos grupos sociais produtores de saberes" (TARDIF, 2002, p. 38). Assim, para muitos, o conhecimento construído através das disciplinas e dos livros pode ser redentor, ou seja, a única forma de refletirem sobre suas futuras práticas.

O fenômeno (estágio) faz parte dos saberes disciplinares, pois compõe o conjunto de disciplinas ofertada pelos currículos dos cursos de formação inicial. Ainda destacamos que as vivências construídas nos estágios podem se tornar o que Tardif (2002), Gauthier et al. (2006) e Pimenta (2005) caracterizam como saberes experienciais ou saber da experiência.

Eu aprendi muito fazendo os estágios, se não fossem os estágios eu não saberia a metade do que eu consegui hoje, novas experiências que tem me ajudado (Estudante Maria).

Krug et al. (2008), observa que o estágio é idealizado como um emaranhado de vivências significativas através das quais identifica, seleciona, destaca os conhecimentos necessários e válidos para a atividade profissional. Mas ainda ressaltamos que essas incorporações e interiorizações (DUBAR, 1996; BERGER; LUCKMANN, 2012) são subjetivas a cada sujeito. Ou seja, partindo da singularidade de cada acadêmico, podemos analisar que nem todos tenham a mesma profundidade de reflexão acerca das experiências.

Podemos caracterizar os saberes da experiência como saberes subjetivos, onde cada sujeito produz e configura o seu de acordo com suas necessidades, mas não podemos esquecer das relações que estão intrínsecas nas experiências, ou seja, da coletividade que rodeia os futuros docentes. Neste sentido, concordamos com Dubet (1994), quando afirma que as experiências sociais são primeiramente individuais, mas são também definidas pelos coletivos que traçam caminhos comuns, como no caso das experiências escolares, das experiências operárias ou outras mais. Na realidade, o que é coletivo são as condições de fabricação das experiências sociais. Mas cada um de nós continua sendo uma forma singular destes quadros coletivos. Como tudo na vida social, as experiências são individuais e coletivas. 


\section{Formação inicial e o mundo de trabalho: o que esperam professores em formação?}

Nesta última categoria buscamos apresentar quais as expectativas que os estudantes possuem em relação à docência ao se aproximarem do fim da formação inicial. Analisamos que os acadêmicos apresentam certa insegurança em imaginar o que lhes espera ao sair da formação inicial. Ou seja, as diversas realidades escolares; estudantes; planos e as relações com os demais sujeitos da escola deixa os futuros professores com interrogações, angústias e algum temor. Mas ainda assim, esse inesperado pode vir a causar um certo encontro com a profissão, ou seja, é através dos desafios que aprendem e se constituem professores. Neste sentido, é comum entre os estudantes deste estudo que almejem trabalhar em escolas bem estruturadas, esperando que essas ofereçam apoio e subsídio básicos para suas práticas educativas. O estudante João argumenta que se espelha em suas experiências com os estágios.

Eu espero passar por vários colégios, mas que eu pegue um colégio igual o dos meus dois últimos estágios, bem estruturado, com apoio pedagógico, apoio dos demais docentes. Porque chegar de paraquedas no colégio e ter que se virar sem ajuda nenhuma é mais difícil. Por mais que tenha dificuldades, o apoio é essencial, facilitador para tua pratica (João).

Para Conceição, Frasson e Borowski (2014), a organização escolar possui grande importância ao acolher o professor iniciante e, ainda, por oferecer o apoio necessário para que ele possa se sentir seguro dentro da organização. É por meio das interações sociais que se estabelecem os mecanismos de rotina nesta realidade de vida cotidiana (BERGER; LUCKMANN, 2012).

Podemos identificar nas falas dos estudantes Maria e Bruna que a indagação que se colocam ao saberem que irão ingressar no magistério é o sentimento de ilusão. Ou seja, cogitam uma certa tensão entre o que esperavam e o que idealizavam com a realidade posta nas diversas culturas.

O que aprendemos na formação inicial é tudo lindo maravilhoso, mas tu chega na escola e não é bem aquilo. Às vezes tu não consegue chamar a atenção da turma, as vezes tu não consegue explicar a atividade do jeito que eles consigam entender, é difícil. Tem que se adaptar primeiro a escola, ao estilo da escola para tu conseguir dar aula tem que se adaptar aos alunos, para depois colocar na prática, colocar na teoria (Maria).

Desde que estou na universidade sempre escutei meus colegas comentarem que as escolas não são um mar de flores, que eles não te dão espaço, material, não te dão condições. Mas quando passamos a ver com nossos olhos, vimos o quanto é triste, é desgastante e desmotivante (Bruna). 
Este fenômeno pode ser compreendido por Huberman (1995) e Marcelo Garcia (1999) como choque com o real ou choque cultural. Com base na fala das colaboradoras Maria e Bruna, o choque com o real existe, a realidade encontrada na sala de aula se distancia da realidade idealizada pelos acadêmicos em formação. Ainda podemos ressaltar na fala da colaboradora Maria a necessidade de se "adaptar", como ela coloca, à escola e aos alunos. Ao sinalizar isso, a colaboradora parece não entender a necessidade de analisar e conhecer o capital cultural dos alunos e a cultura escolar. Ou seja, a dificuldade dela se encontra em conciliar as necessidades dos sujeitos com as suas aulas. Entendendo a escola tal como sustenta Pérez Gómez (2001), como uma complexa e fluida encruzilhada de culturas, destacamos a importância dos professores se embarrarem nas culturas existentes dentro da escola, com o propósito de entenderem as necessidades e singularidades de cada sujeito social.

Outro elemento central ao analisarmos as expectativas dos futuros professores está relacionado ao modelo de contratação adotado pelo município de Criciúma e pelo próprio estado de Santa Catarina. Segundo Conceição, Frasson e Borowski (2014), essa condição de contrato, denominado $\mathrm{ACT}^{9}$, assenta ao professor uma situação de instabilidade e incertezas, já que todos os anos precisam participar de processo seletivo para o ingresso no magistério. Esta incerteza é acompanhada pela dúvida de saber em qual escola irá atuar e o tempo que irá permanecer nela.

Eu estou me formando e eu pretendo conseguir pegar ACT (risos), triste realidade de o professor esperar a ser chamado (Clara).

Eu me identifiquei bastante no ensino médio, mas o problema é que quando vamos para a escolha, não podemos escolher em dar aula só para o ensino médio, eles vão te mandar pra onde tem, e quando tem. (Bruna).

Eu quero seguir carreira, eu não quero parar, quero continuar. Mas ser ACT é muito difícil, isso é um pouco complicado, eu estava comentando com minhas colegas hoje tem uma professora que trabalha que já é formada há uns quatro anos, e ela tem duas pós-graduação com bastante especialização e conseguiu somente 10 horas, eu acho um pouco injusto. Acho injusto a classificação, dos ACTs (Maria).

Esse procedimento de contratação temporária é o destino da maioria dos professores em formação no estado de Santa Catarina. Ser ACT é não saber destino nos próximos anos, ou nos próximos meses quando se trata de substituição de outros professores, é estar imerso de angústias e medos em todo processo de classificação e escolha de vagas. É estar, ainda,

${ }^{9}$ Os professores nessa condição de trabalho, possuem um contrato com data de início e fim nas escolas, que é estabelecido pela instituição contratante - a prefeitura municipal. Os professores ACT não necessariamente precisam estar formados, ou seja, podem estar cursando o ensino superior e prestar o processo seletivo. 
muitas vezes, desconectado da cultura escolar, do contato com a organização escolar e da interação mais intensa com o corpo docente e com a comunidade escolar onde estão inseridos, prejudicando a compreensão aprofundada das realidades culturais existentes.

Esta particularidade no processo de contratação de professores é um fato que interfere no contato com a organização escolar e integrar-se ao corpo docente. No campo da organização pedagógica, os professores iniciantes em contrato temporário passam a implementar propostas sugeridas pelos professores nativos da escola. Este parece ser o primeiro momento em que a socialização se desvela, pois a programação das propostas educacionais nem sempre corresponde às expectativas e anseios dos docentes (CONCEIÇÃO; FRASSON; BOROWSKI, 2014, p. 476).

Assim, compreendemos que a ânsia por se formarem e conseguirem certa estabilidade e segurança profissional faz com que os docentes procurem realizar concursos públicos e até escolherem outros campos de atuação, que não seja professor ACT.

Eu espero me firmar, vou continuar estudando, vou fazer primeiro Pósgraduação. Aí depois tentar concursos, porque sinceramente vida de ACT é desgastante, é por classificação, corremos o risco de nem conseguir (Marta).

$\mathrm{Na}$ fala da colaboradora Marta, podemos destacar que os professores possuem como meta essa busca pela efetivação, de conseguir a tão sonhada estabilidade. Valle (2003) enfatiza que a carreira docente, em especial o magistério público, apresenta como uma das suas características básicas a seleção de seus profissionais por meio de concurso público, proporcionando efetivação e, consequentemente, conquista de estabilidade no trabalho.

$\mathrm{O}$ acolhimento dos futuros professores se torna aspecto central para auxiliar e contribuir no processo de constituição dos professores iniciantes. O estudante João apresenta uma proposta de acompanhamento aos professores na qual sugere que haja uma troca entre os mais experientes e os iniciantes, a fim de constituir espaços e estratégias de suporte às angustias e anseios inicias.

Eu penso na seguinte questão, a graduação te prepara para o mercado de trabalho, mas tu chega lá e é uma coisa totalmente diferente, às vezes tudo ao contrário do que tu aprendeu e do que tu tem como concepção. Acho que poderia haver um projeto do governo talvez, ou da própria universidade de acompanhar esses docentes, após um ou dois anos de formado, na fase inicial da carreira, onde os professores mais experientes, ou da graduação te auxiliem, te ajudem nesse enfrentamento com a realidade quanto tu sai daqui, acho que isso seria muito importante e diminuiria a desistência dos professores. Um acompanhamento, uma conversa, uma troca de diálogos entre quem está iniciando e quem já está a mais tempo (João). 
Contreras (2012) aponta que o diálogo reflexivo e a interação, em educação, só pode ser interpretada com a manutenção de diálogos com outras pessoas, seja com alunos, com colegas ou com outros agentes sociais.

\section{Considerações transitórias}

A partir deste estudo, compreendemos as influências na escolha pela docência: relação com antigos professores, bolsas de estudo, contato com a prática esportiva e até a limitada oferta de outras opções. Essas influências apresentadas são elementos de socialização e que, portanto, repercutem nos processos formativos dos estudantes colaboradores desse estudo. Podemos destacar que a preocupação e intencionalidade com a escolha da sua futura profissão pode acarretar em encontros e desencontros dentro do curso de formação inicial.

Ainda, os saberes disciplinares e curriculares são comuns e singulares a cada estudante, além de serem principalmente subjetivos. Ou seja, cada acadêmico se remete ou mobiliza o saber necessário para sua prática, o que mais é significativo a eles. Esses saberes são elementos centrais para debater as experiências dos estudantes. Os mesmos afirmam que são nas disciplinas que se apoiam para poderem dar conta de suas tarefas na escola.

Destacamos que o processo formativo do futuro professor se inicia antes mesmo da escolha do magistério, em suas experiências como estudantes da escola básica, sob influência dos antigos professores e também de seus familiares. Ao ingressar nos cursos de formação inicial esse processo se expande, pois são inúmeros os contextos em que eles possuem aproximação: estágios, práticas como componentes curriculares, diálogos e disciplinas e currículo do próprio curso. Neste sentido, compreendemos que o constituir-se professor é um processo carregado de ações e sentidos, movido por saberes que mobilizam a prática pedagógica por meio das reflexões críticas sobre o seu exercício docente.

\section{REFERÊNCIAS}

BERGER, P.; LUCKMANN, T. A construção Social da Realidade: tratado de sociologia do conhecimento. 34. ed. Petrópolis: Vozes, 2012.

CALDEIRA, A. M. S. A formação de professores de Educação Física: quais saberes e quais habilidades? Revista Brasileira de Ciências do Esporte, Florianópolis, v. 22, n. 3, p. 87103, maio, 2001. 
CONCEIÇÃO, V. J. S. da; FRASSON, J. S.; BOROWSKI, E. B. A influência da socialização sobre o percurso docente dos professores de Educação Física no início da carreira. Pensar a Prática, Goiânia, v. 17, n. 2, p. 472-484, jan./mar. 2014.

CONTRERAS DOMINGO, J. El saber de la experiencia en la formación inicial del profesorado. Revista Interuniversitaria de Formación del Profesorado, n. 78 (27,3) p. 125136, 2013.

CONTRERAS DOMINGO, J.; PÉREZ DE LARA, N. La experiencia y la investigación educativa. In: CONTRERAS DOMINGO, José. Investigar la experiencia educativa. Madri, p. $21-86,2010$.

DENZIN, N. K.; LINCOLN, Y. S. Introdução: a disciplina e a prática da pesquisa qualitativa. In: DENZIN, N. K.; LINCOLN, Y. S. (Orgs.). O planejamento da pesquisa qualitativa: teorias e abordagens. 2. ed. Porto Alegre: Artmed, p. 15-41, 2006.

DUBAR, C. A Socialização. Construção das identidades sociais e profissionais. Porto: Porto Editora, 1996.

DUBET, F. Sociologia da experiência. Lisboa: Instituto Piaget, 1994.

FLORES, M. A. Algumas reflexões em torno da formação inicial de professores. Educação, Porto Alegre, v. 33, n. 3, p. 182-188, setembro 2010.

GAUTHIER, C. et al. Por uma teoria da pedagogia: pesquisas contemporâneas sobre o saber docente. 2. ed. Ijuí: Editora Unijuí, 2006.

HUBERMAN, M. Ciclo de vida profissional dos professores. In: NÓVOA, A (org.) Vida de Professores. 2. ed. Porto: Porto Editora, p. 31-61, 1995.

KRUG, H. N. et al. Estágio Curricular Supervisionado em Educação Física: significado e importância sob a ótica dos acadêmicos do curso de licenciatura. In: Simpósio Nacional De Educação Física, XXVII, 2008, Pelotas. Anais... Pelotas: UFPEL, 2008.

GARCIA, C. M. Formação de Professores: Para uma Mudança Educativa. Marcelo, Garcia. Estudo sobre estratégias de inserção profissional na Europa. Revista Iberoamericana de Educación, n. 19, p. 101-144, 1999.

MARCELO GARCIA, Carlos. O professor iniciante, a prática pedagógica e o sentido da experiência. Formação Docente, Belo Horizonte, v. 03, n. 03, p. 11-49, ago./dez., 2010.

MIZUKAMI, M. da G. N. Docência, Trajetórias Pessoais e Desenvolvimento Profissional. In: REALI, Aline Maria de Medeiros Rodrigues. MIZUKAMI, M. G. N. Formação De Professores. São Carlos: EDUFSCAR, 1996.

MOLINA NETO, V. La cultura del profesorado de Educación Física de las escuelas públicas de Porto Alegre. 489 f. Tese (Doutorado). Programa de Doctorado "Innovació curricular i formació del profesorat” Bienio 1992-1994, UB, Barcelona, 1996. 
MOLINA NETO, V. Etnografia: uma opção metodológica para alguns problemas e investigação no âmbito da Educação Física. In: MOLINA NETO, V.; TRIVIÑOS, A. N. S. A pesquisa qualitativa em Educação Física: alternativas metodológicas. 3. ed. Porto Alegre: Ed. Sulina, p. 113-146, 2010.

NEGRINE, A. Instrumentos da coleta de informações na pesquisa qualitativa. In: MOLINA NETO, Vicente; TRIVIÑOS, Augusto Nibaldo Souza. A pesquisa qualitativa na Educação Física: alternativas metodológicas. 3. ed. Porto Alegre: Sulina, p. 61-93, 2010.

PÉREZ GÓMEZ, A. I. A cultura escolar na sociedade neoliberal. Porto Alegre, ARTMED, 2001.

PIMENTA, S. G. Professor: formação, identidade e trabalho docente. In: PIMENTA, S. G. (org.) Saberes pedagógicos e atividade docente. 3. ed., São Paulo: Cortez, p. 15-34, 2002.

PIMENTA, S. G. Formação de Professores: identidade e saberes da docência. In: PIMENTA, S. G (Org.) Saberes pedagógicos e atividade docente. São Paulo (SP): Cortez, 2005.

SILVA, V. S. de O. e; ALMEIDA JUNIOR, A. S. de. O Lugar da Experiência Docente no Processo De Formação Inicial Em Educação Física: Um Relato Autobiográfico. In: III Congresso Sudeste de Ciências do Esporte, Mega Eventos esportivos no Brasil: seus impactos e a participação popular, Anais... Niterói - RJ, 2010.

SOARES, D. H. P. A escolha profissional do jovem e do adulto. São Paulo: Summus, 2002.

TARDIF, M. Saberes docentes e formação profissional. 4. ed., Petrópolis, RJ, Vozes, 2002.

TARDIF, M.; RAYMOND, D. Saberes, tempo e aprendizagem do trabalho no magistério. Educação \& Sociedade, Campinas, v. 21 n. 73, dez., 2000.

TRIVIÑOS, A. N. S. Introdução à pesquisa em ciências sociais: a pesquisa qualitativa em educação. São Paulo: Atlas, 2008.

VALLE, I. R. do. A era da profissionalização: formação e socialização profissional do corpo docente de $1^{\mathrm{a}}$ a $4^{\mathrm{a}}$ série. Florianópolis: Cidade Futura, 2003.

\section{Como citar este artigo:}

CONCEIÇÃO, Victor Julierme Santos; FRASSON, Jessica Serafim; WITTIZORECK, Elisandro Schultz; KRUG, Hugo Norberto. Experiências docentes na formação inicial: o processo formativo de professores de educação física. Revista Ibero-Americana de Estudos em Educação, Araraquara, v. 14, n. 4, p. 2106-2122, out./dez., 2019. e-ISSN: 1982-5587. DOI: https://doi.org/10.21723/riaee.v14i4.9748

Data de Submissão: 22/04/2019

Revisões requeridas: 05/07/2019

Aceite em: 11/07/2019

Publicado em: 02/09/2019 